\title{
Association of Birth Weight with Gestational Age and Maternal Measles Antibodies
}

\author{
Ahmadu $\mathrm{BU}^{1}$, Shemiya $\mathrm{Y}^{2}$, Anita $\mathrm{G}^{3}$, Ubong $\mathrm{S}^{4}$, Abdulrahman $\mathrm{B}^{5}$, Amina $\mathrm{B}^{6}$, Iranyang $\mathrm{Y}^{7}$, Rabi $Z^{8}$, Chekwube $\mathrm{MA}^{9}$, \\ Fatima $\mathrm{MU}^{10}$, Gidado $\mathrm{A}^{11}$
}

\begin{abstract}
Introduction: Maternal measles antibody (MMA) offers protection against measles in early childhood, however, certain determinants of this antibody lives much to be desired. The aim of the study were to determine the association between birthweight (BW) and gestational age (GA), to assess the relationship between $B W$ and $M M A$, to correlate GA with MMA and to examine the combined effects of BW and GA on MMA. Material and Methods: The work was a hospital-based crosssectional descriptive study. Babies were enrolled using systematic random sampling method. The babies BW was measured using the bassinet scale; enzyme linked immunosorbent assay was used to determine MMA. GA of babies was determined using the mothers' last menstrual period (LMP) or by Dubowitz score or by Obstetric ultrasound scan. Data were analysed using SPSS statistical software version 16, Illinois, Chicago USA and a computer program for epidemiologist PEPI version 3.01. Spearman's correlation (rho), Kendall's rank correlation (tau b) and Jonckheere-Terpstra test of association of ordinal variables were determined. Univariate analysis was used to investigate the combine effects of BW and GA on MMA. Likely-hood ratio Chisquare ( $\chi 2$ ) was used for categorical data. Goodman-Kruskal index rank order of predictive association (tau) of ordinal data was also calculated. Results: 200 babies were enrolled, 101 (50.5\%) were males and 99 (49.5\%) females. 169 babies (84.5\%) had normal BW, 117 (58.5\%) were delivered at term. The mean BW was 3.04 $(0.58)$ at $95 \% \mathrm{Cl}(2.96-3.12) \mathrm{kg}$. Association between BW and GA was significant $(p=0.003)$, the predictive value for the association was also significant $(p=0.039)$. Significant correlation was also observed between GA and MMA ( $p<0.001)$. Conclusions: There was a significant association between $\mathrm{BW}$ and GA and MMA correlated well with $\mathrm{GA}$.
\end{abstract}

Key words: Birthweight, Gestational age, Maternal measles antibody, Babies, Maiduguri, North-Eastern Nigeria.

\section{Introduction}

$\mathrm{M}$ easles is the principal cause of vaccine-preventable deaths in infants in the world. The Global burden of disease (GBD) project in 2000, estimated that of 1.7 million deaths associated with vaccine preventable disease, measles accounted for about
'Dr. Baba Usman Ahmadu (MBBS, MHPM, FMC Paed), Head of Department, Paediatrics, Federal Medical Centre Yola, P.M.B 2017, Yola, Adamawa State, Nigeria. Formerly of the Department of Paediatrics University of Maiduguri Teaching Hospital. Visiting consultant Paediatrician Abubakar Tafawa Balewa University Teaching Hospital Bauchi and Federal Medical Centre Jalingo, Taraba state, Nigeria, ${ }^{2}$ Yohanna Shemiya (MBBS), ${ }^{3}$ Godfrey Anita (MBBS), ${ }^{4}$ Shammah Ubong (MBBS), ${ }^{5}$ Bello Abdulrahman (MBBS), ${ }^{6}$ Bello Amina (MBBS), ${ }^{7}$ Yanshak Iranyang (MBBS), ${ }^{8}$ Zabadi Rabi (MBBS), ${ }^{9}$ Madu Anselem Chekwube (MBBS), ${ }^{10}$ Mana Umar Fatima (MBBS), ${ }^{11}$ Auta Gidado (MBBS) All from the Department of Paediatrics, Federal Medical Centre, Yola, Adamawa state, Nigeria.

\author{
Address for correspondence: \\ Dr. Baba Usman Ahmadu \\ Head of Department, Paediatrics, \\ Federal Medical Centre Yola, P.M.B 2017, \\ Yola, Adamawa State, Nigeria \\ E-mail:ahmadu4u2003@yahoo.com \\ Phone: +2348033668948
}

\section{How to cite}

Ahmadu BU, Shemiya $Y$, Anita G, Ubong S, Abdulrahman B, Amina B, Iranyang Y, Rabi Z, Chekwube MA, Fatima MU, Gidado A. Association of birth weight with gestational age and maternal measles antibodies. J Nepal Paediatr Soc 2015;35(1):6-12.

\section{doi: http://dx.doi.org/10.3126/jnps.v35i1.10461}

This work is licensed under a Creative Commons Attribution 3.0 License.

\section{(c) (7)}

$46 \%^{1,2}$. Several countries in Africa, SouthEast Asia, Europe, Eastern Mediterranean and Western Pacific regions recorded the resurgence of measles whenever measles control practices were relaxed ${ }^{3}$. Cases of measles were reported across continents 
and countries of the world like Cameroon, Bangladesh and the United States of America to mention just a few 3,4,5,6. Maternal measles antibody (MMA) protect infants from measles and are transferred to foetus from third trimester of gestation, the age at which the weight of the foetus also increases significantly under favourable in utero environment ${ }^{7,8,9}$.

Variation in the prevalence of MMA in babies has been found to be dependent on geographical and socio-demographic factors ${ }^{1,3,10,11}$. Several factors were studied with a view to find reasons for variation within populations. Well-documented ones are prior measles virus (MV) exposure that produces higher MMA than measles immunization. Previous study conducted by Bromberg et al ${ }^{12}$ in 1994, demonstrated that mothers from developing nations had higher levels of MMA than those in developed countries. Another study carried out in the United Kingdom by Brugha et al ${ }^{13}$ in 1996, similarly showed a higher MMA in mothers with a history of natural MV exposure. Other variables that had been studied included socioeconomic status, education, race, parity, age, nutrition and gestational age (GA). All these apart from GA looked at MMA of mothers as a surrogate determinant of measles antibodies in babies ${ }^{8,9,10}$.

Gestational age was found to be associated with different levels of MMA in babies such that preterm babies may have lower levels than their term or postterm counterparts ${ }^{8,9,10}$. Researchers in Sri Lanka and some part of Africa had looked at the influence of birthweight (BW) on MMA of babies; however, the subject matter is still not very clear due to paucity of literatures ${ }^{14-16}$. Moreover, studies showing the combine effects of BW and GA on MMA are almost lacking. Learning more about the association between BW and its combined effect with GA on the starting levels of MMA in babies ${ }^{14-16}$, cannot be overemphasized because of the significance it could have in protecting babies against measles later in infancy and early childhood. Therefore, the aims of this work were four :- 1) to determine the association of BW with $G A, 2$ ) to assess the relationship between $B W$ and $M M A, 3$ ) to correlate GA with MMA and 4) to examine the combine effects of BW, GA on MMA. To the best of our knowledge there are no studies or data on this subject matter especially in Maiduguri, North-Eastern Nigeria; and paucity of information still exist on this issue especially in developing countries of the world after vast literature review.

\section{Material and Methods}

The study was conducted at the Department of Paediatrics, Immunology and Obstetrics unit of the
University of Maiduguri Teaching Hospital (UMTH), Nigeria. The UMTH is a tertiary centre located in North-Eastern Nigeria and a centre of excellence in infectious diseases and immunology. The study area is defined by longitude $13.50 \mathrm{E}$ and latitude $110 \mathrm{~N}$. The characteristic vegetation is that of Sub-sudan and Guinea savannah with an average annual rainfall of $79 \mathrm{~mm}$ and $197 \mathrm{~mm}$ in the northern and southern part of the state. Temperature ranges from $15{ }^{\circ} \mathrm{C}$ to 39.7 ${ }^{\circ} \mathrm{C}$. Being the largest health facility in the region, the UMTH serves as a referral site for the six North-Eastern States and neighboring countries of Chad, Cameroon and Niger Republics. The study was a hospital-based cross-sectional descriptive study of babies recruited from the labour ward of the UMTH.

Participation in this study was voluntary and consenting mothers were selected using systematic random sampling method where the first of every five mother was picked as they presented to the labour ward, using the labour ward register as a sampling frame. Where the first did not fulfill the inclusion criteria, the immediate next mother that qualified was selected. Pregnant women who delivered at the UMTH and consented to the study had their babies enrolled in this work. Sick babies or those whose mothers decline consent were excluded.

The study protocol was reviewed and authorised by the Medical Research and Ethics Committee of UMTH in compliance with guidelines of the Helsinki declaration on biomedical research on human subjects. Assistance of linguistics interpreters of informed consent form in local languages mainly (Kanuri and Babur) were sought for due to low literacy rate in Maiduguri ${ }^{17}$. Parents had unlimited liberty to deny consent without any consequences while confidentiality was maintained.

Sample Size and collection of specimens: The minimum sample size was determined using a statistical formula ${ }^{18}$, which compares means and standard deviation based on Jacob Cohen effect size of 0.2 , alpha levels of 0.05 and power of $90 \%$. This equalled 130; however, $50 \%$ of the sample size was added to maximize power. Thus the total sample size for this study was 200 babies.

The BW of babies was measured using the bassinet weighing scale that has a sensitivity of $50 \mathrm{gms}$ set at zero mark. Birthweight $>3.99$ kilograms $(\mathrm{kg})$ was classified as macrosomia, $2.5-3.99(\mathrm{~kg})$ was normal, $1.5-<2.5(\mathrm{~kg})$ was low BW, $1.0-<1.5(\mathrm{~kg})$ was very low $B W$ and $<1.0(\mathrm{~kg})$ was extremely low BW ${ }^{19}$. Gestational age of babies was determined using the mothers' last menstrual period or by Dubowitz score or by Obstetric ultrasound scan where available ${ }^{20}$. 
Two millilitres (m/s) of neonatal cord blood were obtained at birth using sterile disposable five $\mathrm{mls}$ syringe under aseptic technique, and placed in sterile plain bottles. Sera were separated after centrifuging these blood samples at 5000 revolutions per minute (rpm) for five minutes. The sera were used to estimate MMA (U/ml) by enzyme linked immunosorbent assay (ELISA). All sera collected were pooled in a refrigerator at $-20^{\circ} \mathrm{C}$ until the time of MMA assay.

Data analyses were performed using SPSS statistical software version 16, Illinois, Chicago USA and a computer program for epidemiologist PEPI version 3.01. Descriptive data were presented in Tables and Figures were used for illustration. Spearman's correlation (rho) for BW and MMA and Kendall's rank correlation (tau b) for GA and MMA were determined. Jonckheere-Terpstra test of association between BW and MMA of babies was also investigated. Univariate analysis was used to investigate the combine effects of BW and GA on MMA. Likely-hood ratio Chi-square ( $\chi 2$ ) was used to compare categorical variables. GoodmanKruskal index rank order of predictive association (tau) for BW and GA of babies was also determined. A p value $<0.05$ was considered significant.

\section{Results}

Two hundred babies were enrolled in this study. There were 101 (50.5\%) males and 99 (49.5\%) females. The male to female ratio was 1.02:1. Majority of the babies 169 (84.5\%), 117 (58.5\%) were within the range for normal BW and term respectively (Table 1 ). The babies mean BW was 3.04 (0.58) at $95 \% \mathrm{Cl}(2.96-3.12)$ $\mathrm{kg}$.
Table 1: Showing birthweight and gestational age characteristics of 200 babies

\begin{tabular}{|c|c|c|}
\hline Characteristics & Frequency & Percentage (\%) \\
\hline \multicolumn{3}{|l|}{ Babies BW (kg) } \\
\hline VLBW & 4 & 2.0 \\
\hline LBW & 20 & 10.0 \\
\hline Normal BW & 169 & 84.5 \\
\hline Macrosomia & 7 & 3.5 \\
\hline \multicolumn{3}{|c|}{ Gestational age (weeks) } \\
\hline Preterm & 49 & 24.5 \\
\hline Term & 117 & 58.5 \\
\hline Postterm & 34 & 17.0 \\
\hline
\end{tabular}

$B W=$ Birth weight, $V L B W=$ Very low birth weight, $L B W=$ Low birth weight

Table 2 shows BW and GA distribution of the subjects. Association between BW and GA was significant $(p=0.003)$. Overall, the Goodman-Kruskal index of predictive association (tau) for BW and GA was significant ( $p=0.039)$; that for predictive association of variable classified in the rows (BW) was $(p=0.012)$ and columns (GA) was ( $p=0.052$ ) respectively.

Table 3 shows BW, GA, median MMA and confidence intervals. Figure 1 and 2 below depicts pictorial area of relationship between BW, MMA and GA. Speaman's correlation (rho) for BW and MMA was 0.400 but Jonckheere-Terpstra test of association between these variables was not significant ( $p=0.087$ ). Though Kendall's rank correlation (tau b) for GA and MMA was significant $(p<0.001)$, the combine effects of BW and GA on MMA using univariate analysis was not significant $(p=0.587)$.

Table 2: Showing birth weight and gestational age distribution of the study cohorts

\begin{tabular}{|c|c|c|c|c|c|}
\hline \multirow[t]{2}{*}{ BW (Kg) } & \multicolumn{3}{|c|}{ Gestational age (weeks) } & \multirow[b]{2}{*}{ Total } & \multirow[b]{2}{*}{$p$ value } \\
\hline & $\begin{array}{c}\text { Preterm } \\
\text { n (\%) }\end{array}$ & $\begin{array}{l}\text { Term } \\
\mathrm{n}(\%)\end{array}$ & $\begin{array}{c}\text { Post term } \\
\text { n (\%) }\end{array}$ & & \\
\hline VLBW & $4(2.0)$ & - & - & $4(2.0 \%)$ & - \\
\hline LBW & $6(3.0)$ & $10(5.0)$ & $4(2.0)$ & $20(10 \%)$ & $0.017^{*}$ \\
\hline Normal BW & 39 (19.5) & $100(50.0)$ & $30(15.0)$ & $169(84.5 \%)$ & 0.721 \\
\hline Macrosomia & - & $7(3.5)$ & - & $7(3.5)$ & $0.028 *$ \\
\hline Total & $49(24.5 \%)$ & $117(58.5 \%)$ & $34(17 \%)$ & $200(100 \%)$ & - \\
\hline
\end{tabular}

$p$ value $^{a}=$ likely-hood ratio Chi-square $(\chi 2)$ trend, (Overall likely-hood ratio Chi-square $\left.(\chi 2)=19.559, p=0.003\right), *^{*}=p$ value $<0.05$ (significant), BW = Birth weight, VLBW = Very low birth weight. 


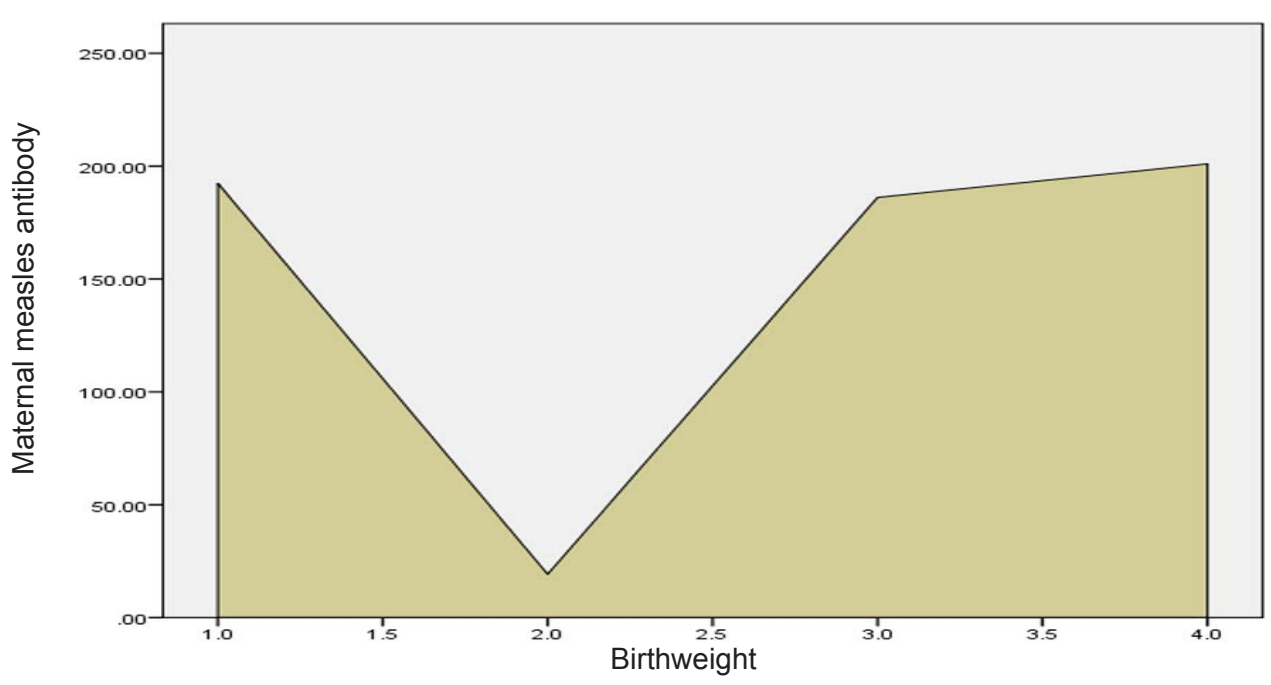

1 = Very low birthweight, 2 = Low birthweight, 3 = Normal birthweight, 4 = Macrosomia

Fig 1: Graphical area showing the relationship between maternal measles antibody and Birthweight

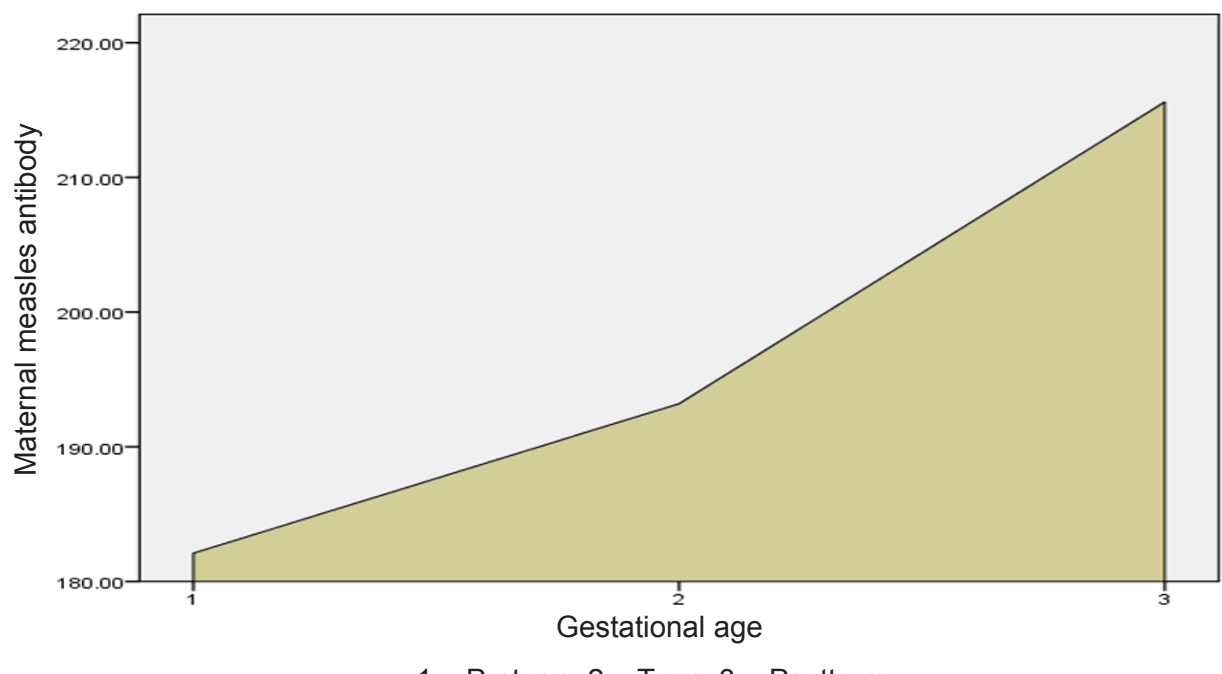

1 = Preterm, 2 = Term, 3 = Postterm

Fig 2: Graphical area showing the relationship between maternal measles antibody and gestational age

Table 3: Showing birth weight, gestational age and maternal measles antibody profiles of the babies

\begin{tabular}{|l|c|c|}
\hline Parameters & Median MMA (U/ml) & 95\% Cl (U/ml) \\
\hline BW (kg) & & $9.51-375.49$ \\
\hline VLBW & 192.50 & $140.76-217.64$ \\
\hline LBW & 179.20 & $172.69-199.60$ \\
\hline Normal BW & 186.14 & $80.68-261.32$ \\
\hline Macrosomia & 201.00 & - \\
\hline value ${ }^{\text {b }}$ & 0.087 & $168.70-195.30$ \\
\hline GA (weeks) & & $9.50-375.50$ \\
\hline Preterm & 182.10 & $189.76-240.60$ \\
\hline Term & 193.20 & - \\
\hline Post-term & 215.60 & \\
$p$ value ${ }^{c}$ & $<0.001 *$ & \\
\hline
\end{tabular}

$p$ value ${ }^{b}=$ Jonckheere-Terpestra test, $p$ value ${ }^{c}=$ Kendall's rank correlation (tau b), BW $=$ Birth weight, GA $=$ Gestational age, $*=p$ value $<0.05$ (significant), VLBW = Very low birth weight, LBW $=$ Low birth weight. 


\section{Discussion}

Majority of babies in this study had their BW within the normal range and were delivered at term. This may not be unconnected to increased awareness and patronage of antenatal care (ANC) services by women during pregnancy. This view agreed with that of researchers at Sylhet, Omani Medical College Hospital in $2010^{5}$. Nigeria's country health system record has shown that up to 61 percent of pregnant women had at least one ANC visit and about half of these women had skilled attendant receiving their babies at the time of delivery ${ }^{21}$. Both preventive and intervention activities with regard to maternal health are conducted during ANC that could have led to healthy women carrying healthy adequate weight babies to term.

Comparing BW of babies with MMA was not significant in current study. Similar observation was made by other workers where they reported that, MV exposure and measles immunizations as chief determinants of MMA could mask other influencers of measles antibody like $\mathrm{BW}^{8}$. In support of this, some authors associated measles with lifelong antibodies and others argued that even measles immunization gives antibodies that could last up to four decades, and possibly lifelong 8,9,17,22. Moreover, our study population was found in measles endemic region, which further buttresses MV exposure and measles immunization as principal determinant of $\mathrm{MMA}^{8,17,21}$. The former through boosting effect of MV and the latter through measles antibody mediated passive humoral immunity. During the third trimester of pregnancy, MMA are actively passed in mother-foetal pairs ${ }^{8,9,10}$. This possibly explains the levels of MMA observed in VLBW, LBW and advancing GA of babies that make up our study population. The relationship between GA and MMA has been well published ${ }^{8-10}$. Term and posterm babies usually have higher MMA because of the recruitment and upward regulation of MMA receptors associated with foetal maturity. Gain in MMA receptors is known to ferry more of these antibody across the placenta to the foetus.

Other investigators, however, had found that BW of babies was directly proportional with $\mathrm{MMA}^{23}$. Foetal adaptation mechanisms could be the probable reason for their findings because more placentomes are recruited as the weight of the foetus increased resulting to increased placental volume ratio ${ }^{24}$. This would enable increased transplacental transfer of MMA in mother-foetal pair. However, several other colleagues have debated on the issue of foetal weight versus placental size correlation as a determinant of substrate transfer to the foetus ${ }^{25}$. They believed that substrate transfer to the foetus is not just a serial but a programmed parallel and complex developmental event of the foetus. Therefore, there is the need for further research in this aspect.

Our work has shown that BW was linearly related with GA of babies; however, no significant observation was made between MMA and BW. Similarly, the combine effect of BW and GA yielded no significant effect on MMA in present work. From this finding, it can be deduced that GA rather than BW may be a better determinant of MMA. Since BW and its combined effect with GA did not contribute significantly towards MMA generation, the principal determinants of measles antibody in babies may rest with their mothers. As such these babies may need measles immunization because their MMA levels could be as a result of measles campaign as was seen in Sabongidda-Ora, Edo State, and other parts of Nigeria and also other measles endemic sites ${ }^{8,26}$. Measles antibodies due to measles campaign rapidly decay leaving these babies susceptible to measles early in infancy ${ }^{8}$. Therefore, more health facility should be modeled in such a way that measles immunization can be administered to children in addition to mass campaigns.

\section{Conclusions}

Birthweights vary directly with GA and MMA was found to have a linear relationship with GA; however, no significant relationship was established for BW alone or in combination with GA on MMA.

\section{Limitations}

This work was conducted in a single hospital (UMTH); therefore, there is the need to be cautious in generalizing the data of this study. More so, the study did not look at MMA that was associated with maternal measles immunization or prior wild type MV infection of mothers. This was because of lack of facility in our centre that could differentiate these antibodies one from another. More so, most of these mothers were un-able to remember whether they had measles immunization or wild type MV infection during childhood.

\section{Recommendations}

Based on the findings of this work, it is recommended that multiple centers' should be involved in future research of this nature to enable generalization of findings. Also, future work should address co- 
founders like maternal measles immunization and maternal prior wild type MV infection.

Acknowledgements: We thank Professor Al Rabasa for reviewing the manuscript. We also acknowledged the kind help of staffs of Paediatric, Immunology and Obstetric department of the UMTH.

Funding: Nil

Conflict of Interest: None

Permission from IRB: Yes

\section{Contributors}

BUA conceived, designed and statistically interpreted the data of the study; BUA, YS, GA, and $\mathrm{SU}$ assessed the paper and wrote the draft report; however, all authors were also involved in the critical revision of the manuscript.

\section{References}

1. Levels \& trends in child mortality report 2011: Estimates developed by the UN Inter-agency Group for Child Mortality Estimation. New York, NY, United Nations Children's Fund, 2011 (http://www. childinfo.org/files/Child_Mortality_Report_2011. pdf, accessed 11 March 2012).

2. Ahmed PA, Babaniyi IB, Otuneye AT. Review of childhood measles admissions at the National Hospital, Abuja. Niger J Clin Pract 2010;13:413-6.

3. Global measles and rubella strategic plan 20122020. World Health Organization, Switzerland 2012.

4. Fact Sheet: Update: Measles. United States, January-July 2008.

5. Kamar S, Chowdhury O, Murshed M, Hasan R. Effect of Gestational Age and Nutrition on Transplacental Transfer of Measles Antibody. Med Today 2010;22:1-5.

6. Félicitée $N$, Mathurin $T$, Andreas C, Roger D, Innocent K, Tetanye $\mathrm{E}$, et al. Morbidity and Mortality from Measles in Cameroonian Children: Implications for Measles Control. Open Area Studies J 2011;4:7-13.

7. Rosemary OU, Egri-Okwaji MTC. Neonatology. In: Azubuike JC, Nkanginieme K EO eds. Paediatrics and Child Health in a Tropical Region. $2^{\text {nd }}$ ed. Owerri: African Educational Services: 2007. p. 157160.

8. Cáceres VM, Strebel PM, Sutter RW. Factors determining prevalence of maternal antibody to measles virus throughout infancy: A review. Clin Infect Dis 2000; 31:110-19.

9. Nicoara C, Zach K, Trachsel D, Germann D, Malter L. Decay of passively acquired maternal antibodies against Measles, Mumps, and Rubella viruses. Clin Diagn Lab Immunol 1999;6: 868-71.

10. Scott S, Cumberland P, Shulman CE. Neonatal measles immunity in rural Kenya: the influence of HIV and placental malaria infections on placental transfer of antibodies and levels of antibody in maternal and cord serum samples. J Infect Dis 2005;191:1854-60.

11. Black FL, Berman LL, Borgoño JM, Capper A, Carvalho AA, Collins $C$, et al. Geographic variation in infant loss of maternal measles antibody and prevalence of rubella antibody. Am J Epidemiol 1986;124:442-52.

12. Bromberg $K$, Shah B, Clark-Golden $M$, Light $H$, Marcellino L, Rivera $M$, et al. Maternal immunity to measles and infant immunity at less than twelve months of age relative to maternal place of birth. $J$ Pediatr 1994; 125:579-81.

13. Brugha R, Ramsay M, Forsey T, Brown D. A study of maternally derived measles antibody in infants born to naturally infected and vaccinated women. Epidemiol Infect 1996;117:519-24.

14. Wesumperuma HL, Perera AJ, Pharoah POD, Hart CA. The influence of prematurity and low birthweight on transplacental antibody transfer in Sri Lanka. Ann Trop Med Parasitol 1999;93:169-77.

15. Okoko JB, Wesumperuma HL, Hart CA. The influence of prematurity and low birthweight on transplacental antibody transfer in a rural West African population. Trop Med Int Health 2001; 6:529-34.

16. Singh J, Khare S, Prabha S. Transplacental transfer of measles antibody in Delhi. Indian Pediatr 1998;35:1187-91.

17. Ampofo K, Omotara BA. Epidemiology of measles in Borno State. Annals of Borno 1987;4:217-27.

18. Browner WS. Estimating sample size and power. In Hulley SB, Cummings SR, Grady D, Hearst N, Newman TB editors. Designing Clinical Research. $2^{\text {nd }}$ ed. Philadelphia: Lippincott Williams \& Wilkins; 2001. P. 65-84.

19. Uche N. Assessment and care of the newborn. In: Azubuike JC, Nkanginieme K EO eds. Paediatrics and Child Health in a Tropical Region. $2^{\text {nd }}$ ed. Owerri: African Educational Services: 2007. p. 163177. 
20. Dubowitz, L., Dubowitz, V. and Goldberg, C. Clinical assessment of gestational age in the newborn infant. J Pediatr 1970;77:1-10.

21. World Health Organisation. Country health system fact sheet Lagos, Nigeria 2006.

22. Griffin DE, Bellini WJ. Measles. In: Brooks GF, Butel JS, Morse SA, editors. Jawetz, Melnick and Adelbergs Medical Microbiology. $22^{\text {nd }}$ ed. Chicago: Mcgraw-Hill co; 2001.p. 481-4.

23. Abraham V, Jose OA, Herminio H, Daniel G, Pablo C, Colarossi A. Loss of Maternally Acquired Measles Antibodies in Well-Nourished Infants and
Response to Measles Vaccination. Am J Pub Health 1990;80:736-38.

24. Stephenson T, Symonds ME. Maternal nutrition as a determinant of birth weight. Arch Dis Child Fetal Neonatal Ed 2002;86:46.

25. Armitage JA, Taylor PD, Poston L. Experimental models of developmental rogramming: Consequences of exposure to an energy rich diet during development. J Physiol 2005;565:38.

26. Odusanya OO, Alufohai JE, Meurice FP, Ahonkhai VI. Determinants of vaccination coverage in rural Nigeria. BMC Pub Health 2008;8:381-6. 